\title{
A OUVIDORIA COMO INSTRUMENTO DE AVALIAÇÃO E MELHORIA DA QUALIDADE DOS SERVIÇOS OFERECIDOS PELA SECRETARIA MUNICIPAL DA EDUCAÇÃO DE QUIXADÁ-CE
}

\author{
Maria Elenilda Gomes Rabêlo de Oliveira ${ }^{1}$
}

\begin{abstract}
Resumo
O presente artigo objetiva descrever uma experiência realizada de 2013 a 2016 enquanto Ouvidora da Secretaria da Educação de Quixadá-CE. Inicialmente, discorreremos sobre a criação da Ouvidoria da SMEQ (Secretaria Municipal da Educação de Quixadá), os serviços oferecidos e o nível de satisfação dos usuários. Para isso, foi feita uma pesquisa através de questionário com 20 (vinte) questões abertas para avaliar o índice de satisfação para com o serviço. Para a coleta de dados foram analisados os 20 (vinte) questionários e ainda alguns registros da Ouvidoria, especificamente no ano de 2013, os quais nos permitiram avaliar o trabalho do setor como uma direção para o planejamento de atividades, detecção dos problemas, instituição de tomadas de decisão, que consequentemente conduzem à melhoria do atendimento na busca pela satisfação e o bem-estar do usuário. Com a análise dos dados constatou-se que, com a criação da Ouvidoria, os serviços da SMEQ têm se revelado uma ferramenta fundamental de feedback para a Gestão Pública, particularmente para a Educação do município de Quixadá-Ce.
\end{abstract}

Palavras-chave: Ouvidoria. Avaliação. Qualidade.

DOI:10.37814/2594-5068.2018v1.p143-150

1 Graduada em Letras pela Universidade Estadual do Ceará. Pós-graduada em Língua Portuguesa, também pela UECE. Mestra em Educação. (elen_rabelo@yahoo.com.br) Rua Padre José Bezerra Filho, 285. Bairro Alto da Boa Vista - Quixadá-CE. CEP 63908-715. (elenildarabeloelenilda@gamil.com) 


\begin{abstract}
This article aims to describe an experience held in 2013 to 2016 as an Ombudsman for the Quixadá-CE Secretariat of Education. Initially, we will discuss the creation of the SMEQ's Ombudsman's Office (Quixadá Municipal Education Office), the services offered and the level of user satisfaction. For this, a questionnaire was searched with 20 (twenty) open questions to evaluate the satisfaction index for the service. In order to collect data, we analyzed the 20 (twenty) questionnaires and some records from the Ombudsman's Office, specifically in the year 2013, which allowed us to evaluate the work of the sector as a direction for planning activities, detecting problems, decision making, which consequently lead to improved service in the search for satisfaction and the well-being of the user. With the analysis of the data, it was verified that with the creation of the Ombudsman's Office, the SMEQ services have proved to be a fundamental feedback tool for Public Management, especially for Education of the municipality of Quixadá-Ce.
\end{abstract}

Keywords: Ombudsman's Office. Evaluation. Quality. 


\section{INTRODUÇÃO}

Em 28 de agosto de 2013, o Decreto Municipal $n^{\circ} 2.211 .001 / 2013$ e a Lei $n^{\circ}$ 2.599/2013 validaram o Regimento Interno da Secretaria Municipal da Educação de Quixadá, bem como a nova estrutura e composição organizacional. Dentro dessa nova organização, no mesmo documento, seção IV, art. 20, está descrita a célula da Ouvidoria, com o objetivo de oferecer uma educação de qualidade, detectando possíveis falhas administrativas, nos mais diversos setores, para então providenciar os devidos ajustes dentro do processo gerencial.

Este artigo tem como objetivo expor observações a respeito de uma pesquisa feita a partir da criação dessa Ouvidoria, com foco no grau de satisfação dos usuários da SMEQ (Secretaria Municipal da Educação de Quixadá) quanto aos aspectos comportamento (do próprio usuário), responsabilidade e respeito da gestão para com o servidor e a comunidade escolar.

Para desenvolver a presente pesquisa, foi elaborado um questionário de 20 (vinte) questões abertas direcionadas a 20 (vinte) usuários, os quais fizeram uso do serviço através do próprio site da Ouvidoria da SMEQ e posteriormente foram convidados a responder voluntariamente o referido questionário.

Dentre os usuários que responderam o questionário estavam funcionários efetivos do município (professores, diretores de escolas, motoristas do transporte escolar), pais, alunos e comunidade externa que direta ou indiretamente usufruem do serviço público. A amostra foi elaborada com o objetivo de avaliar a implantação da Ouvidoria da SMEQ, suas dificuldades e, principalmente, acompanhar o comportamento e a satisfação do usuário com o serviço fornecido pela Ouvidoria.

Essa foi a primeira atividade de um trabalho que pretende ser periódico e possibilitará o acompanhamento e a evolução dos serviços prestados pela Ouvidoria, a fim de melhorar o atendimento, satisfazendo significativamente o usuário.

Importante lembrar a importância da Secretaria Municipal da Educação de Quixadá em ter criado esse canal de comunicação de escuta ao cidadão, reativando o conceito de liberdade de expressão e reivindicação por melhores condições de trabalho e, consequentemente, melhorias para a educação no município.

Este artigo pretende dar destaque aos usuários da Ouvidoria e refletir sobre eles. Na primeira parte, vamos tratar do conceito de Ouvidoria e as atribuições do Ouvidor. Na segunda parte, discorreremos sobre as características do município de Quixadá, sua localização geográfica e número de alunos atendidos pela rede municipal de ensino.

Posteriormente, discutiremos os dados relacionados ao acesso dos usuários, por que procuram ou por que não procuram os serviços de uma Ouvidoria. Na última parte, trataremos dos dados relacionados à satisfação dos usuários com os serviços prestados e concluiremos com algumas indagações e reflexões sobre a correspondência do gestor público para com o usuário da Ouvidoria.

\section{CONCEITO DE OUVIDORIA, PERFIL E FUNÇÃO DO OUVIDOR}

Antes de adentrar as questões voltadas para a pesquisa em si, vale fazer um corte para que possamos estabelecer uma definição de Ouvidoria, mostrar o perfil e a função do Ouvidor. 
Segundo o Manual da Ouvidoria da SMEQ, Ouvidoria, como a própria palavra estampa, provém do verbo "ouvir". No sentido geral, sua função é ouvir críticas, reclamações, sugestões, elogios. Tem função mediadora. É um espaço que acolhe e faz ressoar a voz dos atores que atuam no setor público. É também responsável pelo recebimento, acompanhamento de opiniões, comentários, críticas e elogios de todos os que participam direto ou indiretamente do serviço público, sendo responsável também por fazer chegar ao usuário uma resposta das instâncias administrativas implicadas.

Junto à Ouvidoria, surge a figura do Ouvidor, o qual exercerá um elo entre o cidadão e a Administração Pública, mediante uma comunicação acessível e direta. Para exercer seu papel de articulador e mediador, o Ouvidor deve apresentar um perfil diferenciado. Deverá ser competente em suas atribuições, conhecedor dos trâmites administrativos do órgão em que irá atuar.

Alguns atributos pessoais são fundamentais para compor o perfil de um Ouvidor: possuir integridade moral; paciência no trato com o público; empatia com o usuário; possuir espírito de colaboração e cortesia; ser imparcial e praticante do bom senso diante das informações que são recebidas e não propagá-las a ponto de constranger o usuário; ter capacidade crítica e analítica; apresentar coerência nas tomadas de decisão; fazer uso da discrição em suas ações.

Dentre as atribuições do Ouvidor está a de, acolhendo as denúncias e reclamações sobre os atos administrativos considerados injustos e contra o mau atendimento por parte do funcionalismo público, atuar em busca de soluções que venham a corrigir as injustiças e minimizar a imagem negativa do órgão que representa. Em seguida, responder as demandas apresentadas à Ouvidoria, como forma de garantir o respeito ao cidadão, prestando conta das providências que foram tomadas e para quem foram encaminhadas, por competência.

NACFUR (2006, p. 02) ao referir-se ao objetivo menciona que:

\begin{abstract}
A história dessa relação empresa/cliente mostra que, sempre que o cliente é atendido em suas demandas, todos ganham: a empresa, o gestor e o público. Assim, o que se espera e se quer é que as partes desta importante equação, cliente + empresa, com a intermediação da Ouvidoria, quando for preciso, encontrem o ponto de equilíbrio e a solução ideal para todas as questões.
\end{abstract}

As palavras de NACFUR (2006) referem-se claramente ao serviço de uma Ouvidoria privada, o que não deixa de ser um ponto comum entre Ouvidoria pública e privada.

O que se pretende mostrar é que, sendo pública ou privada, percebe-se a importância dessa relação entre o usuário e a instituição que está oferecendo os serviços. O Ouvidor precisa, antes de tudo, colocar-se no lugar do usuário, procurando entender o problema, o que nem sempre é fácil, por estarem em situação incomum. Mesmo assim, precisa demonstrar interesse e oferecer esclarecimento sobre as providências que serão tomadas, para que seja selado um vínculo de confiança.

\title{
2 CONHECENDO O MUNICÍPIO DE QUIXADÁ E SUA ATUAL ESTRUTURA DE ENSINO
}

Quixadá é um município brasileiro do Estado do Ceará, marcado por suas formações rochosas, por isso denominado também de "Terra dos Monólitos". Terra dos famosos escritores Jáder de 
Carvalho e Rachel de Queiroz, que morou no distrito de Daniel de Queiroz, famoso por seus pontos turísticos, como o Açude Cedro, o Santuário Nossa Senhora Rainha do Sertão, Chalé da Pedra e Pedra do Cruzeiro. Com a denominação Quixadá e subordinado ao município de Quixeramobim, foi criado pela Lei Provincial n 1.305, de 5 de novembro de 1869. Já em 27 de outubro de 1870, foi elevado à categoria de vila com a denominação de Quixadá pela Lei Provincial $n^{0} 1.347$, desmembrado do município de Quixeramobim.

Com uma área de 2.019,833 km² e uma população de 80.604 habitantes, Quixadá teve como primeiros habitantes os índios tapuias e canindés, que aos poucos foram abandonando a região, à medida que seus domínios eram conquistados pelos brancos.

De acordo com os dados estatísticos da Secretaria Municipal da Educação de Quixadá, CE, o município conta hoje com 56 escolas na zona urbana e rural, distribuídas entre Ensino Fundamental I com um total de 5.106 alunos, Ensino Fundamental II com 4.724 alunos, Ensino Infantil com 2.633 alunos e Educação de Jovens e Adultos com 96 alunos, perfazendo um total de 12.559 alunos, com 587 professores em sala de aula. Conta ainda com o Centro de Apoio à Educação Inclusiva de Quixadá, atendendo crianças com necessidades especiais.

Nas escolas públicas do município de Quixadá, 79,07\% das turmas são da Educação Básica do Ensino Fundamental (CENSO, 2016), o que caracteriza o acréscimo do número de alunos nos últimos anos justificado pela nova estrutura organizacional, que tem seus objetivos articulados com base em legislações, como o Plano Nacional de Educação de 2015 e a LDB (Lei de Diretrizes e Bases da Educação) de 1996.

$\mathrm{Na}$ atual gestão, 2013 até o presente ano, tem-se investido muito nos recursos das novas tecnologias, objetivando maior ambientação para os docentes e discentes, no sentido de favorecer o processo de aprendizagem. Tais mudanças dão-se em grande número com a implementação de laboratórios de informática, com computadores ligados à internet e ambientes climatizados, além de livros didáticos e materiais como jogos eletrônicos e jogos educativos.

\section{OS PORQUÊS DO USO E DO NÃO USO DA OUVIDORIA - COMPREENDENDO O PROCESSO}

A pesquisa realizada apresentou 20 (vinte) questões abertas a 20 (vinte) usuários da Ouvidoria, os quais tentaram esclarecer os "porquês" do uso ou do não uso dos serviços da Ouvidoria. Todas as informações colhidas serviram de embasamento para a realização dos resultados a que se pretendia chegar.

Em sua maior parte, as pessoas que registraram suas opiniões disseram ser bem acolhidas, escutadas e que, na maioria das vezes, seu problema teria sido solucionado através de mecanismos utilizados pelo Ouvidor, uma vez que ele, enquanto usuário, não teria acesso a eles.

Outros responderam que jamais procurariam uma Ouvidoria, já que podem tratar dos seus problemas diretamente com o "Gestor Maior" (Secretário da Educação), o que, para 1\% das pessoas pesquisadas, seria perda de tempo.

Ficou notório, pela maioria das respostas, que os usuários, ao se sentirem insatisfeitos com a 
prestação dos serviços, mobilizam-se para manifestar suas queixas e reclamações junto ao serviço da Ouvidoria; entretanto, isso não ocorre em relação aos elogios, que quase nunca são objeto de notificação.

Diante das respostas desses usuários em relação à necessidade de expor seus conflitos, emergiram algumas indagações importantes para a análise da pesquisa:

Quais as demandas dos usuários junto ao serviço da Ouvidoria da SMEQ?

Como a equipe da administração procede a partir das notificações das demandas dos usuários na Ouvidoria?

De que maneira as demandas dos usuários são utilizadas para a melhoria da qualidade da educação?

Baseado nessas indagações, foi feito um levantamento das demandas dos usuários na Ouvidoria. A maioria das queixas vem do transporte escolar (60\%); merenda escolar (10\%); abuso de poder $(20 \%)$; tratamento com os alunos $(10 \%)$, como mostra o gráfico abaixo.

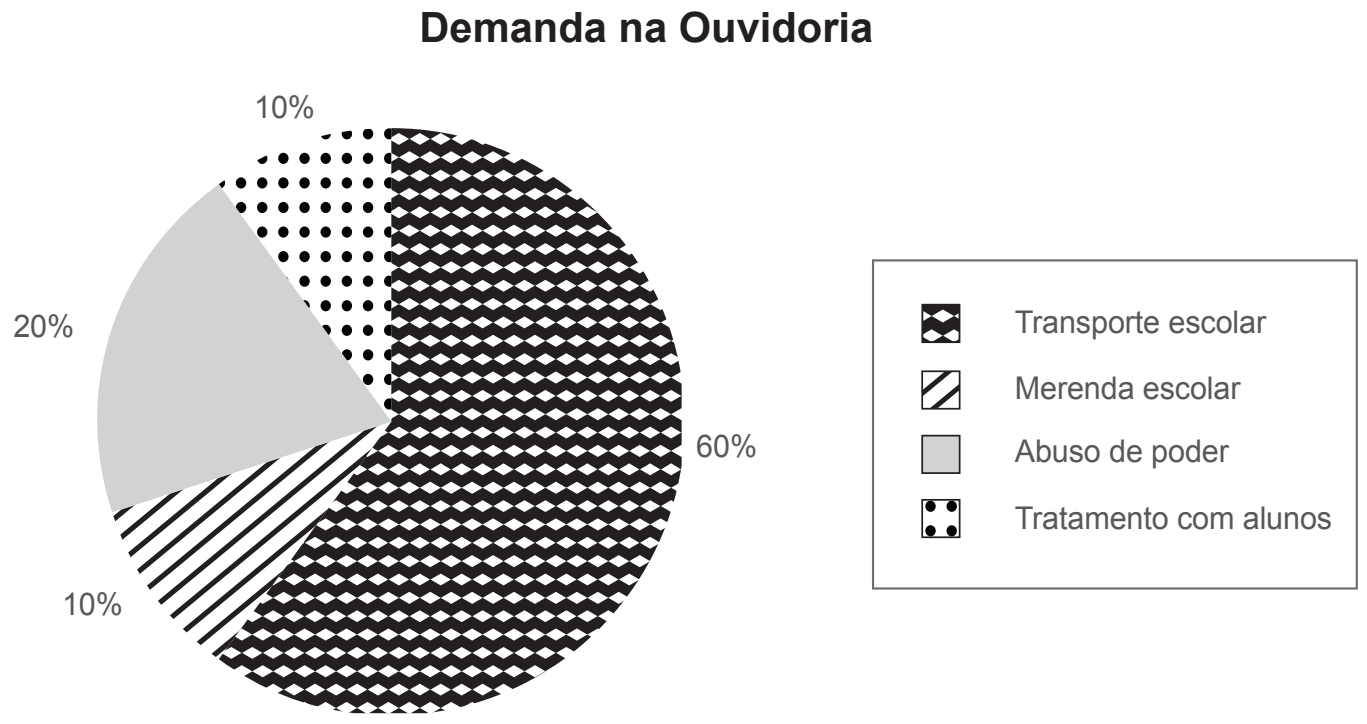

Para responder às duas últimas indagações, aplicou-se também um pequeno questionário aos gestores que recebem essa demanda da Ouvidoria. Estes responderam que se sentem satisfeitos em poder contribuir, quando possível, para a resolução dos conflitos. Focaram ainda a importância da Ouvidoria como instrumento estratégico e inovador, e concordaram que as manifestações dos usuários devem ser efetivamente acolhidas, possibilitando atuar no sentido de mudanças e organização. A citação a seguir vem reforçar com mais exatidão os relatos dos contribuintes citados anteriormente.

Todo governo deve admitir que a Administração possa falhar, portanto há que se ter espaço para que o público tenha o direito de exigir melhores padrões de produtividade administrativa. Assim, se qualquer erro ocorre, a organização responsável deve corrigi-lo e encontrar meios de prevenir futura ocorrência. O sistema público deve garantir alterna- 
tivas para o recebimento das reclamações ou queixas individuais contra a Administração Pública e os funcionários públicos devem ser sensíveis às críticas aos seus desempenhos. (ALVES JR., 2002, p. 40).

Isso mostra que as prefeituras, para garantir uma melhor qualidade de seus serviços, precisam usar estratégias que possam garantir o bem-estar do servidor e de toda a comunidade que necessita e usufrui dos serviços públicos.

\section{A SATISFAÇÃO DOS USUÁRIOS COM A OUVIDORIA DA SMEQ - RESULTADO E DISCUSSÃO}

Mediante observações feitas pelos usuários no questionário aplicado, quanto à satisfação com o serviço oferecido pela Ouvidoria e os agentes envolvidos, percebe-se que a avaliação foi muito positiva. A pesquisa deixa claro que a satisfação nesse caso está relacionada com o acesso àquilo que se "buscou" e com a realização ou não de algumas das expectativas que o usuário levou para esse atendimento.

Cabe aqui fazer uma referência ao sentimento do usuário que, ao informar sua insatisfação, passa o sentimento de que desejava que sua reivindicação fosse levada em consideração, devendo o órgão ter tempo suficiente para resolver o problema. Quando é ouvido com consideração, fica satisfeito com a forma como foi recepcionado, mesmo que a solução para seu problema não corresponda à sua expectativa inicial. A pesquisa também mostra o oposto: quando o usuário não tem acesso ao que "foi buscar", seja por ele mesmo ter mudado a compreensão do assunto, seja por não haver disponibilidade do serviço e, mesmo assim sai satisfeito, isso mostra que valorizou algo mais que a realização da demanda.

Enquanto observava o funcionamento da Sala da Ouvidoria, foi possível perceber o constrangimento mediante a presença de outra pessoa que não fosse a do Ouvidor. Os motivos para esse comportamento vão desde o fato de que problemas vinculados à rede municipal geram receio de punição por parte dos gestores, uma vez que tachados de reclamões, na visão cultural desses servidores, serão punidos de alguma forma, o que não cabe discutir aqui neste artigo.

\section{CONSIDERAÇÕES FINAIS}

Conclui-se este artigo ressaltando a importância de fazermos uma reflexão sobre o trabalho da Ouvidoria e o grau de satisfação gerado nos usuários. Ressaltamos também a contribuição desse estudo para o processo de valorização das Ouvidorias, cujo propósito é melhorar a qualidade dos serviços. A Ouvidoria da SMEQ tem se revelado uma ferramenta fundamental de feedback para a Gestão Pública, particularmente para a Educação do município de Quixadá-Ce.

Os usuários participantes da pesquisa veem a Ouvidoria como uma direção para o planejamento de suas atividades, pois na detecção dos problemas institui-se a tomada de decisão, consequentemente conduzindo à melhoria do atendimento na busca pela satisfação e o bem-estar do usuário. 


\section{REFERÊNCIAS}

ALVES JÚNIOR, Mário Nelson. A contribuição estratégica das Ouvidorias para melhoria dos serviços prestados pelas organizações: um estudo de caso na Secretaria de Estado e Saúde de Santa Catarina. Florianópolis, 2002.

BRASIL. Lei de Diretrizes e Bases da Educação. Lei n 9.394/96, de 20 de dezembro de 1996.

NACFUR, Anis. A realidade de uma Ouvidoria. Disponível em: <http://www.Ouvidoria. unicamp.br/textos/A_Realidade_de_uma_Ouvidoria.pdf> Acesso em: 19 dez. 2013.

SECRETARIA MUNICIPAL DA EDUCAÇÃO DE QUIXADÁ-CE. Regimento Interno. Dez. 2013. 